\title{
Gestão documental e resgate da memória na Justiça do Trabalho: preservação documental é direito do cidadão e dever do Estado ${ }^{1}$
}

\author{
Maria Cristina Diniz Caixeta* \\ Maria Aparecida Carvalhais Cunha**
}

\begin{abstract}
Resumo
A implantação de programas de preservação documental e a estruturação dos serviços de arquivo, sob uma perspectiva histórica, são fenômenos relativamente recentes nas instituições brasileiras. Esse movimento em prol da guarda e disponibilização dos documentos públicos, inseridos no rol de patrimônio nacional, lançou luz sobre um problema urgente: a necessidade de investimentos em políticas de gestão e preservação documental que garantam a salvaguarda de nossos registros históricos. Assim, um dos objetivos deste artigo é oferecer elementos para a discussão dessas práticas de resgate da memória histórica nas instituições públicas brasileiras à luz da experiência desenvolvida em um ramo específico do Poder Judiciário: a Justiça do Trabalho.
\end{abstract}

Palavras-chave: Memória; História; Arquivo; Gestão e preservação documental; Acesso; Informação; Pesquisa.

Alguém deve rever, escrever e assinar os autos do passado antes que o tempo passe tudo a raso.

Cora Coralina

O surgimento de programas de gestão e preservação documental nas instituições públicas brasileiras é um fenômeno relativamente recente em nossa história administrativa. Esse impulso remonta à década de 1990 e já demonstra sua importância e impacto na produção acadêmica atual. Reforçadas pela política nacional de arquivos -

\footnotetext{
${ }^{1}$ Preceito da Carta de Intenção do III Encontro Nacional da Memória da Justiça do Trabalho, realizado em Recife, nos 4 e 5 de setembro de 2008.

* Juíza Titular do Trabalho do Tribunal Regional do Trabalho (TRT) $3^{\text {a }}$ Região; mestre em Direito e Processo do Trabalho pela Pontifícia Universidade Católica de Minas Gerais (PUC Minas); mestre em Relaciones de Trabajo pela Universidade Castilha La Mancha (Espanha). Presidente do Fórum Nacional de Preservação da Memória da Justiça do Trabalho (MEMOJUTRA); integrante do Comitê de Preservação da Memória da Justiça do Trabalho do Tribunal Superior do Trabalho (TST); conselheira Titular do Conselho Nacional de Arquivos (CONARQ); Supervisora da Comissão de Gestão Documental do TRT $3^{\text {a }}$ Região. Professora das Faculdades Integradas de Pedro Leopoldo (FIPEL) e do Centro Universitário UNA.

** Pesquisadora da Escola Judicial/Centro de Memória do Tribunal Regional do Trabalho de Minas Gerais; especialista em Memória e Cinema pela Universidade Federal de Minas Gerais (UFMG), especialista em História da Cultura e da Arte pela Universidade Federal de Minas Gerais (UFMG) e, especialista em História e Culturas Políticas pela Universidade Federal de Minas Gerais (UFMG).
} 
instituída pela Lei $\mathrm{n}^{\circ}$ 8.159, de 8 de janeiro de 1991 - tais iniciativas lançaram luz sobre um sério problema presente em nossas organizações públicas que, por décadas, acumularam documentos sem políticas de gestão nem investimentos em suas estruturas arquivísticas. Em muitos casos, os arquivos institucionais apresentavam-se como depósitos abarrotados de documentos sem instrumentos de pesquisa nem ações voltadas para preservação. Essa conjuntura adversa comprometia o desempenho institucional e ameaçava importantes registros de nossa História.

$\mathrm{O}$ crescimento da produção documental nas últimas décadas do século $\mathrm{XX}$ agravou a situação e trouxe à tona riscos de perdas irreversíveis para os fatos históricos de nossa época, ante o acúmulo desordenado de informações. Fez-se necessário pensar alternativas para solucionar tais questões que tendiam a se agravar com o passar do tempo. A gestão documental entrou na pauta de discussões e demonstrou a necessidade de políticas públicas consistentes que reestruturassem os serviços de guarda e a gestão das informações produzidas nas instituições.

Diante desse contexto, a Lei 8.159, de 1991, não por acaso, denominada "Lei de Arquivos", foi um marco significativo e imprimiu novos rumos à preservação e à relevância dos setores de arquivo dentro das organizações. A gestão de documentos, tanto públicos quanto privados, passou a ser estruturada em uma política nacional com competências bem definidas. Os primeiros artigos da Lei $n^{\circ} 8.159$ já apontam para os novos parâmetros a serem seguidos, explicitando responsabilidades e definindo o significado de arquivo e documento:

\footnotetext{
Art. $1^{\circ}$ É dever do Poder Público a gestão documental e a proteção especial a documentos de arquivos, como instrumento de apoio à administração, à cultura, ao desenvolvimento científico e como elementos de prova e informação.

Art. $2^{\circ}$ Consideram-se arquivos, para os fins desta lei, os conjuntos de documentos produzidos e recebidos por órgãos públicos, instituições de caráter público e entidades privadas, em decorrência do exercício de atividades específicas, bem como por pessoa física, qualquer que seja o suporte da informação ou a natureza dos documentos. (BRASIL, 1991).
}

A guarda de documentos deixou de ser atribuição restrita aos arquivos e institutos criados para esse fim. Os empreendedores, concessionários de serviços e produtores de informações são também instâncias responsáveis pela preservação de seus acervos. A prestação de serviços e, principalmente, de serviços públicos, não se esgota em si, tem continuidade na salvaguarda dos documentos gerados e, principalmente, na 
prestação de informações a quem de direito. Nos artigos seguintes, a Lei $\mathrm{n}^{\mathbf{0}} 8.159$ dirige-se aos arquivos públicos e privados, definindo como públicos, art. $7^{\circ}$ "os conjuntos de documentos produzidos e recebidos, no exercício de suas atividades, por órgãos públicos de âmbito federal, estadual, do Distrito Federal e municipal em decorrência de suas funções administrativas, legislativas e judiciárias." No art. $7^{\circ}, \S 1^{\circ}$, fica claro que "são públicos os conjuntos de documentos produzidos e recebidos por instituições de caráter público, por entidades privadas encarregadas da gestão de serviços públicos no exercício de suas atividades." A seguir, identifica os documentos públicos, art. $8^{\circ}$, como: "correntes, intermediários e permanentes," definindo, em parágrafo do artigo $8^{\circ}, \S 3^{\circ}$, como permanentes, "os conjuntos de documentos de valor histórico, probatório e informativo que devem ser definitivamente preservados, atribuindo aos documentos permanentes a condição de inalienáveis e imprescritíveis", art. $10^{\circ}$. E, no art. 25, tratando das responsabilidades, dispõe com clareza que: ficará sujeito à responsabilidade penal, civil e administrativa, na forma da legislação em vigor, aquele que desfigurar ou destruir documentos de valor permanente ou considerado como de interesse público e social (BRASIL, 1991).

Dessa forma, a Lei $\mathrm{n}^{\circ} 8.159$ avança em relação à legislação existente ao identificar a natureza dos documentos, temporalidades de guarda e ao atribuir sanções legais para seu descumprimento. Os acervos institucionais são patrimônios da nação e como tais devem ser tratados.

No âmbito do Poder Judiciário, a redemocratização do país, e, em particular, a promulgação da Constituição de 1988, proporcionaram uma proximidade mais efetiva entre a Justiça e seu usuário: o cidadão. A ampliação dos mecanismos de acesso à justiça possibilitou maior visibilidade a sua atuação, estabelecendo canais de comunicação sólidos com a sociedade e suscitando reflexões acerca de seu funcionamento e significado social.

No decorrer dessas transformações e, quiçá, em consequência delas, houve uma grande sensibilização do Judiciário Brasileiro em resgatar sua trajetória, contextualizá-la e compreendê-la ao longo do processo histórico nacional. Assim, o objetivo deste artigo é oferecer elementos para a discussão dessas práticas de gestão documental nas instituições públicas brasileiras à luz da experiência desenvolvida em um ramo específico do Poder Judiciário: a Justiça do Trabalho. Portanto, pretende-se abordar a trajetória desses programas na justiça trabalhista, refletir acerca de suas estratégias de ação, seu acervo, suas especificidades e contribuições para a preservação documental 
em todo o Judiciário.

Para tanto, é importante considerar duas linhas de ações que desencadearam esse movimento na Justiça do Trabalho. Por um lado, os programas de resgate e registro da Memória conduziram à urgente necessidade de gestão e preservação documental. Por sua vez, a exigência legal que obrigou as instituições a administrarem suas informações e, principalmente, torná-las pública, trouxe à luz importantes registros, muitas vezes inéditos e perdidos ante a desorganização dos setores de arquivo. $\mathrm{O}$ acervo da Justiça Trabalhista remonta ao tempo de sua criação - $1^{\circ}$ de maio de 1941 - e possui fundos documentais administrativos e judiciais representativos das relações entre capital e trabalho pós-revolução de 1930, fonte primária de pesquisa ainda pouco explorada.

Esse acervo é composto por relatórios de atividades, atas, estatísticas, fichas funcionais, documentos administrativos e, principalmente, pelos processos judiciais trabalhistas. Importantes estudos recorrem às potencialidades dessa documentação para pesquisa, principalmente, no que diz respeito aos processos judiciais trabalhistas. Nas palavras da historiadora Sílvia Hunold Lara:

\begin{abstract}
Os processos trabalhistas são parte importante da história do Direito e da Justiça no país e constituem fonte significativa para o conhecimento das formas de exercício do poder, das responsabilidades do Estado e suas iniciativas em defesa dos direitos dos trabalhadores. São também fontes essenciais para os estudos da História da sociedade brasileira, das relações de trabalho, do modo como as pessoas comuns reivindicavam direitos e se relacionavam com a Justiça. Em síntese: são parte importante da história da cidadania no Brasil. $^{2}$ (LARA; MENDONÇA, 2007).
\end{abstract}

Configurando-se como a principal via de acesso dos trabalhadores à justiça as ações trabalhistas "são parte importante da história da cidadania no Brasil," ao dar voz ao trabalhador por meio de suas reivindicações, depoimentos e testemunhos; dar voz ao patrão por meio de sua defesa e manifestações; às categorias por meio de seus sindicatos e; ao Estado; por meio dos julgamentos e sentenças. Os processos são gerados por ações individuais que versam sobre conflitos de natureza trabalhista entre patrões e empregados de diversos segmentos e categorias socioeconômicas; e por ações coletivas que abrangem categorias econômicas amplas delimitadas em sindicatos patronais e de trabalhadores. A documentação possui informações relativas aos principais usuários da Justiça do Trabalho, suas atividades profissionais, seus interesses econômicos e sociais, suas profissões, perfil dos empregados, das empresas e dos sindicatos. Os julgamentos

\footnotetext{
${ }^{2}$ LARA, Sílvia Hunold. Apresentação. I Encontro Nacional da Memória da Justiça do Trabalho Memória e preservação de documentos: direitos do cidadão. São Paulo: LTr, 2007.
} 
mostram as posturas e referências políticas presentes nas decisões finais dos dissídios. As peças do processo registram práticas e relações sociais mais abrangentes, como as experiências cotidianas nos locais de trabalho, nos sindicatos, nas mobilizações coletivas, na esfera privada, possibilitando a análise de costumes e práticas compartilhados e suas repercussões nos comportamentos, visões e sentimentos dos trabalhadores.

O desafio estava posto. A importância desses documentos e o crescente volume de sua produção evidenciaram a urgente necessidade de políticas que estruturassem e garantissem sua salvaguarda. É preciso regulamentar a preservação, a fim de estabelecer patamares comuns de ação e evitar que, por motivos diversos, algumas instituições sejam mais afetas à guarda enquanto outras não se preocupam ou se empenham em efetivar uma preservação consequente e significativa, eliminando parte significativa de nossa história.

Diante dessas considerações e para uma melhor compreensão da trajetória desse movimento na Justiça do Trabalho, vamos dividir nossa discussão em duas vertentes de análise, considerando, por um lado, a criação de Centros de Memória e Memoriais na Instituição e, por outro, a implantação de Programas de Gestão Documental. Uma visão panorâmica demonstra que essas duas ações são complementares: a partir da Gestão Documental, chegou-se aos acervos permanentes e históricos e a partir de propostas de regaste da história, consubstanciadas na criação de Centros de Memória e Memoriais, tornou-se imprescindível organizar a documentação e promover pesquisas que recuperassem suas informações. Essas duas iniciativas aconteceram na Justiça do Trabalho em todo o país de forma simultânea e instigaram iniciativas para regulamentar e normatizar suas ações e divulgar seus resultados.

\section{Os Centros de Memória e Memoriais}

A criação de Centros de Memória e Memoriais na Justiça do Trabalho deve ser analisada em um contexto mais amplo, em que a memória histórica tornou-se referencial para se pensar o papel desempenhado por agentes sociais e econômicos ao longo de sua existência. Nas últimas décadas, o olhar volta-se para o passado, as instituições são tomadas como fatos históricos, e como tais, inseparáveis das circunstâncias que tornaram possíveis sua criação e existência. É importante destacar essa mobilização das próprias instituições em compreender sua história e construir sua 
identidade, conscientizando-se de seu passado e refletindo acerca de sua memória e tradição.

É nessa conjuntura que, no final da década de 1990, o Judiciário Trabalhista iniciou ações voltadas para recuperação de sua História. De forma isolada, os Tribunais Regionais do Trabalho, em seus respectivos Estados, iniciaram a implantação de Centros de Memória e Memoriais. No mesmo período, a Justiça do Trabalho enfrentou desafios - seu sentido e existência foram questionados pela ideologia neoliberal que repelia, em nome da "modernidade" capitalista, qualquer tipo de intervenção ou regulação estatal nas relações entre capital e trabalho. Não foi mera coincidência, portanto, o fato da inflexão da justiça trabalhista, buscando valorizar sua memória e refletir acerca de seu papel na sociedade brasileira, ter ocorrido em um momento de confronto. O desenvolvimento de estudos acerca da tradição e do passado de instituições e agentes sociais apresenta-se como uma maneira fundamental para se pensar o presente e avaliar suas potencialidades futuras ${ }^{3}$. A Justiça do Trabalho voltou seu olhar para o passado em busca de sua história, de seu papel como partícipe e mediadora das relações envolvendo os conflitos entre capital e trabalho no Brasil. Em outras palavras, procurou compreender-se para além de suas portas, contextualizada no tempo e no espaço, e, a partir de então, ser entendida em suas particularidades.

Nessa conjuntura, os Tribunais Regionais da Justiça do Trabalho começaram a organizar e consolidar Centros de Memória e Memoriais, buscando caminhos e parâmetros para a preservação de sua documentação histórica. A partir de um segundo momento, buscou-se, em uma articulação nacional dos diversos Tribunais Regionais do Trabalho e seus Centros de Memória, estabelecer princípios comuns de preservação que estruturassem as iniciativas já implantadas, criando um mesmo programa de ação. Para que essa articulação nacional se consolidasse, seria fundamental que cada Tribunal Regional do Trabalho apresentasse aos demais suas propostas e experiências. O compartilhamento de práticas e conhecimentos mostrou-se como um requisito essencial para estruturação e fortalecimento das políticas de preservação já propostas pelos Tribunais Regionais da Justiça do Trabalho em todo o país. Esse movimento materializou-se na realização de Encontros Nacionais da Memória da Justiça do Trabalho e na criação do Fórum Nacional Permanente em Defesa da Memória da Justiça

\footnotetext{
3 MENEZES, Ulpiano Bezerra de. Culturas Políticas e Lugares de Memória. In: BIAVASCHI, Magda Barros; LÜBBE, Anita; MIRANDA, Maria Guilhermina (Org.). Anais do IV Encontro Nacional da Memória da Justiça do Trabalho - Cidadania: o trabalho da memória. Belo Horizonte (MG): São Paulo - LTr, 2010.
} 
do Trabalho - MEMOJUTRA.

O I Encontro Nacional da Memória da Justiça do Trabalho aconteceu em Porto Alegre, no mês de novembro de 2006, com a participação de integrantes de Centros de Memória e servidores da área de documentação de todo o país. O evento significou marco importante e trouxe, definitivamente, a questão do resgate da história da Justiça do Trabalho para o âmbito nacional. No ano seguinte, no mês de outubro de 2007, aconteceu o II Encontro da Memória, em Campinas. A expressiva adesão dos Tribunais Regionais do Trabalho permitiu um aprofundado debate em torno da preservação e consolidou os Encontros como espaço de trocas de experiências, propulsor de reflexões e iniciativas comuns para a Justiça do Trabalho, em todo o país.

Seguindo essa orientação, foi criado, durante o II Encontro, o Fórum Nacional Permanente em Defesa da Memória da Justiça do Trabalho - Memojutra - com o objetivo de reunir representantes de todas as regionais e entidades afins em encontros regulares, nos intervalos de realização dos Encontros Nacionais. Conforme definido em estatuto, o Memojutra tem o objetivo de implementar ações e gestões junto ao Conselho Nacional de Justiça - CNJ, Conselho Superior da Justiça do Trabalho -CSJT e Tribunal Superior do Trabalho -TST, entre outros, apresentar as demandas dos setores ligados à Memória e também sensibilizar seus representantes da necessidade de implementar políticas públicas consistentes de preservação documental. Dessa forma, o Memojutra configurou-se em importante instância de interlocução e debates, expressando o posicionamento dos Centros de Memória, Memoriais e Programas de Gestão Documental da Justiça do Trabalho.

Em setembro de 2008, aconteceu no Recife, o III Encontro Nacional da Memória da Justiça do Trabalho. Durante o evento, foi perceptível o fortalecimento dos Encontros e a legitimidade do Memojutra como espaço para debates e reflexões. No ano de 2009, o IV Encontro foi realizado em Belo Horizonte, e em 2010 o V Encontro aconteceu em Belém. O próximo Encontro Nacional da Memória da Justiça do Trabalho, em sua sexta edição, acontecerá em Porto Velho - Rondônia, entre os dias 17 e 19 de outubro de 2012, promovido pelo Tribunal Regional do Trabalho da $14^{\mathrm{a}}$ Região - Rondônia e Acre.

Durante os eventos, são discutidas questões metodológicas e práticas relativas a ações que possibilitem uma preservação consequente da documentação na Justiça do Trabalho. Ao final, sempre é aprovada uma Carta de Intenções, remetida a todos os Tribunais Regionais do Trabalho, ressaltando iniciativas essenciais para a 
implementação de políticas viáveis de preservação e elegendo a cidade que sediará o próximo Encontro. O Tribunal Regional do Trabalho, que promove o Encontro Nacional da Memória da Justiça do Trabalho, também publica seus Anais. A publicação registra a Memória dos Encontros e disponibiliza as palestras, cartas de recomendação e apontamentos do evento para pesquisadores e interessados.

\section{Os Programas de Gestão e Preservação Documental}

Os Programas de Gestão Documental, numa perspectiva de preservar as informações produzidas e sob guarda nas instituições, muito contribuíram para alavancar e estruturar políticas arquivísticas mais amplas na Justiça do Trabalho. A gestão de documentos, enquanto normas e procedimentos de organização do fluxo documental, a princípio, deve configurar-se como matéria de cunho funcional e administrativo. Nenhuma organização social contemporânea pode prescindir da informação para o desempenho de suas atividades meio ou fim, portanto, deve gerir e organizar seus documentos. No entanto, a legislação que normatiza a matéria ultrapassou a questão meramente administrativa e responsabilizou as empresas também pela salvaguarda de sua documentação como garantia de direitos e registro histórico. Como bem definido a partir da Lei $n^{\circ}$ 8.159/1991, o cuidado com a documentação não se encerra com o fim da prestação do serviço, as informações não devem ser preservadas apenas para subsidiar as atividades das empresas. Os setores de arquivos, antes considerados simples repositórios de documentos - arquivos mortos, na expressão comum, - assumem a posição de guardiões de importantes informações que vão além das questões funcionais para as quais tais informações foram geradas.

Para zelar por esses importantes registros são necessários estudos, pessoal capacitado, investimentos, enfim, políticas públicas. Diante de tamanho desafio, instâncias competentes mobilizaram-se para conhecimento da situação e para definição de diretrizes eficazes de intervenção. Mostrou-se urgente a proposição de ações com o intuito de implementar programas de gestão documental que atendessem aos preceitos legais e garantissem uma preservação representativa e consequente dos documentos.

Nesse sentido, em 1991, foi criado o Conselho Nacional de Arquivos CONARQ, órgão colegiado vinculado ao Arquivo Nacional, com a atribuição de definir políticas de gestão e preservação documental e normatizar ações para proteção dos documentos de guarda permanente. O Conarq é composto por representantes dos vários 
seguimentos da sociedade, entre os quais, integrantes dos Poderes Judiciário, Executivo e Legislativo.

Conforme preceitos definidos pela Lei $\mathrm{n}^{\circ}$ 8.159, de 1991, e reforçados por diretrizes do Conarq, todas as instituições devem constituir Programas de Gestão Documental e criar Comissões Permanentes de Avaliação de Documentos ${ }^{4}$ - CPADs. Por meio desses instrumentos, as organizações ficam obrigadas a elaborarem Planos de Classificação e Tabelas de Temporalidade para seus documentos. Dessa forma, por exigência legal, toda documentação produzida e recebida nas empresas deve ser classificada e ter seu tempo de guarda definido.

A Justiça do Trabalho já superou essa primeira etapa e, atualmente, os Tribunais Regionais do Trabalho em todo o país já possuem CPADs e já elaboraram Tabelas de Temporalidade para seus registros. Em cada Tribunal Regional da Justiça do Trabalho, as CPADs são compostas por representantes de setores estratégicos na produção, no fluxo e arquivamento de documentos, e, sempre que possível, conta com servidores com formação em História, Direito e Arquivologia.

$\mathrm{O}$ crescente acesso à Justiça reflete-se de forma direta em seus arquivos, cada vez mais processos judiciais são impetrados, solucionados e, consequentemente, arquivados. O aumento da documentação acumulada é apenas um, entre os muitos problemas enfrentados pelos setores de arquivo. Em muitos casos, existe também o descaso das administrações, a escassez de pessoal capacitado, equipamentos apropriados e a falta de espaços físicos adequados. Diante desse cenário, pensar ações e instrumentos para gerir essa documentação tornou-se um grande desafio, seu crescimento trouxe novas questões e a urgente necessidade de alternativas eficazes para sua preservação. Esse significativo aumento da produção documental demonstrou a necessidade de se pensar em instrumentos para sua gestão, pois a guarda indevida de documentos desprovidos de valor legal, administrativo ou histórico, causa prejuízo à sociedade e impacta de forma negativa o acesso às informações.

Portanto, concretizar objetivo de tamanha grandeza requer um trabalho contínuo e metodologias efetivas. Investimentos significativos são necessários para gerir essa massa documental que cresce e se acumula de forma vertiginosa. Como já foi abordado, tal feito demanda profissionais capacitados e recursos públicos para se evitar o risco iminente de se transformar os Arquivos Judiciais em depósitos abarrotados de

\footnotetext{
${ }^{4}$ Art. 18 do Decreto Federal no 4.073, de 3 de janeiro de 2002.
} 
documentos, não resolvendo a questão do acesso e resultando na perda de importantes informações.

É nesse contexto que o Conselho Nacional de Justiça - CNJ - iniciou estudos para implantação de ações de preservação tendo em vista as especificidades da documentação produzida no Judiciário. Como resultado, foi criado o PRONAME Programa de Gestão Documental e Memória do Poder Judiciário do $\mathrm{CNJ}^{5}$, cujo objetivo principal é implementar políticas nacionais de Gestão Documental e de preservação da Memória do Poder Judiciário. O programa foi lançado em 12 de dezembro de 2008, no Arquivo Nacional do Rio de Janeiro. Na mesma ocasião, foi assinado um Termo de Cooperação Técnica entre o CNJ e o Conselho Nacional de Arquivos - Conarq -com o objetivo de desenvolver ações integradas com foco na implantação de um programa nacional de preservação da massa documental do Poder Judiciário. O objetivo é integrar o Judiciário em políticas nacionais de gestão documental que permitam estruturar e normatizar ações de preservação em todo o país. O Proname é composto por representantes de todos os ramos do Poder Judiciário.

Por sua vez, o Conselho Superior da Justiça do Trabalho - CSJT criou um Grupo de Trabalho de Gestão Documental e Memória ${ }^{6}$, o Tribunal Superior do Trabalho - TST instituiu o Programa Nacional de Resgate da Memória da Justiça do Trabalho ${ }^{7}$ e criou o Comitê Gestor do Programa Nacional de Resgate da Memória da Justiça do Trabalho CGMNac-JT. ${ }^{8}$ O objetivo dessas iniciativas é consolidar e normatizar as ações de preservação da Memória Institucional na Justiça do Trabalho em uma estrutura nacional e, dessa forma, evitar uma preservação diferenciada entre as regionais. Para tanto, o CSJT publicou uma Tabela de Temporalidade dos Documentos Única para a Justiça do Trabalho - TTDU/JT ${ }^{9}$ e um Manual de Gestão Documental. ${ }^{10}$ Tais instrumentos estipulam prazos mínimos de guarda e indicam ações que devem ser adotadas por todos, complementando e normatizando os Programas de Preservação já implementados nos Tribunais Regionais do Trabalho.

\footnotetext{
${ }^{5}$ Para a execução das ações do PRONAME, foi instituído pela Portaria/CNJ/ 616, de 10 de setembro de 2009, o Comitê do Programa Nacional de Gestão Documental e Memória do Poder Judiciário, o qual conta com representantes de todos segmentos do Poder Judiciário.

${ }^{6}$ Resolução CSJT no 30, de 24 de novembro de 2006.

${ }^{7}$ Ato Conjunto TST-CSJT n ${ }^{\circ} 11$, de 03 de maio de 2011.

${ }^{8}$ Ato Conjunto TST-CSJT n ${ }^{\circ} 37$, de 25 de novembro de 2011.

${ }^{9}$ Resolução CSTJ n ${ }^{\circ}$ 67, de 30 de abril de 2010.

${ }^{10}$ Ato CSJT n $^{\circ} 262$, de 18 de novembro de 2011.
} 
Importantes passos já foram dados, no entanto, muito ainda temos que caminhar. São grandes as dificuldades impostas pela gestão, e, principalmente, pela definição de tempo de guarda para documentos que tratam questões tão importantes e significativas. O potencial analítico desse acervo transcende o âmbito meramente jurídico, seus registros relatam o percurso e os significados da regulamentação de direitos no Brasil agregados a matérias fundamentais para organização de nossa sociedade: as relações entre capital e trabalho. Finalmente, nesse caso, lidamos ainda com a responsabilidade social, de gerir e avaliar uma documentação que abarca mais da metade da história republicana brasileira. Sãos muitos os desafios, constituir um acervo documental para gerações futuras, requer muita reflexão e cautela.

Dessa forma, desde os primeiros estudos sobre a matéria, uma grande preocupação norteou as ações para guarda dessas informações na Justiça do Trabalho, qual seja, a responsabilidade em estabelecer critérios e normas sob os quais perdurará a memória documental da Instituição. Dois parâmetros iniciais guiaram tais ações, baseados em dois princípios constitucionais. O primeiro princípio é o da obrigatoriedade da prestação jurisdicional pelo Estado e está estritamente ligado à atividade-fim da Instituição, que é julgar e solucionar conflitos. Esse princípio reflete-se na salvaguarda da informação e na construção da prova. A preservação dos documentos é parte integrante do dever estatal de prestar jurisdição, garantir direitos aos cidadãos e prestar informações. O segundo princípio para guarda é o da proteção aos documentos oficiais como bens de valor histórico e social, indo além do valor primário da documentação. Com isso, torna-se imprescindível preservar processos judiciais, documentos administrativos e demais registros da justiça trabalhista. Dessa forma, garante-se instrumento para se escrever a história das relações de trabalho, do Direito e da Justiça do Trabalho no Brasil.

Em 2011, a promulgação da Lei Federal n 12.527, em 18 de novembro de 2011, denominada "Lei de Acesso à Informação Pública", significou mais um importante avanço e ampliou o debate sobre a necessidade de programas de preservação documental nas Instituições públicas brasileiras. A Lei $\mathrm{n}^{\circ} 12.527$ corrobora de forma direta com toda discussão relativa à gestão documental ao regulamentar o direito do cidadão à informação e definir suas formas de acesso. A Lei inova ao pontuar a responsabilidade das Instituições em gerir e disponibilizar suas informações quando requisitada pelos interessados, inclusive estabelecendo prazos, sanções e penalidades a seu descumprimento. A disponibilização dos documentos passa a ser a regra, dessa 
forma, o governo brasileiro dá um significativo passo em direção à transparência das informações públicas e ao cumprimento do direito constitucional de acesso a mesmas sempre que o cidadão julgar necessário, salvo os casos em que a lei classifica como sigiloso.

\section{Considerações finais}

Estudos e pesquisas demonstram as dificuldades enfrentadas pelos setores ligados à preservação da memória e aos arquivos em qualquer esfera da administração pública. Temos naturalmente realidades bem distintas entre as regiões brasileiras, historicamente explicáveis, que refletem literalmente no "tamanho" do dilema que temos em mãos - massas documentais mais ou menos volumosas com mais ou menos recursos para o seu tratamento arquivístico, entre outras questões. Dessa forma, qualquer atividade na esfera da gestão de documentos e resgate da Memória está cercada de obstáculos e desafios, sejam eles de ordem materiais ou ligados a questões culturais da burocracia e da administração pública.

A Justiça do Trabalho completou 70 anos de sua criação no ano de 2011. Sob o ponto de vista de sua trajetória histórica, podemos considerar que alcançou a maioridade, não apenas como órgão judiciário especializado, mas como instituição pública. Os programas de resgate da Memória e de preservação de sua documentação histórica ilustram bem essa afirmação. Apesar do caminho já trilhado, as políticas e ações de preservação documental na Justiça do Trabalho estão em construção e merecem constante reflexão. 


\title{
Document management and history restoration in Labor Justice: document preservation is a citizen's right and a State's duty
}

\begin{abstract}
The implementation of document preservation programs and the structuring of filing, from a historical perspective, are relatively recent phenomena in Brazilian institutions. The organization and retrieval of public documents, inserted in the list of national heritage, shed light on an urgent problem in organizations: the need for investments in document management policies to prevent random and disorganized accumulation of documents in its archives. Therefore one of the goals of this text is to provide elements for discussion about these documentation conservation practices and record of historical memory in our public institutions under the experience developed by a specific branch of the judiciary: the Labor Court.
\end{abstract}

Keywords: Memory; history; archiving; document management and preservation; access; information; research.

\section{Referências}

ARAÚJO, Eneida Melo Correia de; DABAT, Christine; LIMA, Maria do Socorro de Abreu (Org.). III Encontro Nacional da Memória da Justiça do Trabalho. Recife: Nossa Livraria, 2008.

BIAVASCHI, Magda Barros; LÜBBE, Anita; MIRANDA, Maria Guilhermina (Org.). I Encontro Nacional da Memória da Justiça do Trabalho - Memória e preservação de documentos: direitos do cidadão. São Paulo: LTr, 2007.

BRASIL. Lei $\mathbf{n}^{\mathbf{0}}$ 8.159, de 8 de janeiro de 1991. Dispõe sobre a política nacional de arquivos públicos e privados e dá outras providências. Diário Oficial da União, Brasília, 9 de janeiro de 1991. Disponível em: <www.planalto.gov.br/ccivil_03/leis/L8159.htm>. Acesso em: 09 fev. 2012.

BRASIL. Decreto Federal $\mathbf{n}^{\mathbf{0}}$ 4.073, de 3 de janeiro de 2002. Diário Oficial da União, Brasília, 3 de janeiro de 2002. Disponível em: <www.planalto.gov.br/ ccivil_03/decreto/2002/d4073.htm>. Acesso em: 10 mar. 2012.

BRASIL. Resolução CSJT no 30, de 24 de novembro de 2006. Conselho Superior da Justiça do Trabalho, Brasília, 24 nov. 2006. Disponível em: <aplicacao.tst.jus.br/ dspace/handle/1939/862>. Acesso em: 03 abr. 2012.

BRASIL. Resolução CSTJ n 67, de 30 de abril de 2010. Conselho Superior da Justiça do Trabalho, Brasília, 30 abr. 2006. Disponível em: <aplicacao.tst.jus.br/ dspace/handle/1939/7230>. Acesso em: 02 maio 2012. 
BRASIL. Ato Conjunto TST-CSJT no 11, de 03 de maio de 2011. Tribunal Superior do Trabalho/ Conselho Superior da Justiça do Trabalho, Brasília, 3 de maio de 2011.

Disponível em: <www.normasbrasil.com.br/norma/ato-conjunto-11-2011_2649.html>. Acesso em: 07 fev. 2012.

BRASIL. Lei Federal no 12.527, de 18 de novembro de 2011. Diário Oficial da União, Brasília, 18 de novembro de 2011. Disponível em: <www.planalto.gov.br/ ccivil_03/_ato2011-2014/2011/lei/112527.htm>. Acesso em: 09 mar. 2012.

BRASIL. Ato CSJT no 262, de 18 de novembro de 2011. Tribunal Superior do Trabalho/ Conselho Superior da Justiça do Trabalho, Brasília, 18 nov. 2011. Disponível em: <aplicacao.tst.jus.br/dspace/handle/1939/17636>. Acesso em: 15 mar. 2012

BRASIL. Ato Conjunto TST-CSJT no 37, de 25 de novembro de 2011. Tribunal Superior do Trabalho/ Conselho Superior da Justiça do Trabalho, Brasília, 25 nov. 2011. Disponível em: <aplicacao.tst.jus.br/dspace/handle/1939/19357>. Acesso em: 09 jan. 2012.

CAIXETA, Maria Cristina Diniz; CUNHA, Maria Aparecida Carvalhais; DINIZ, Ana Maria Matta Machado (Org.). IV Encontro Nacional da Memória da Justiça do Trabalho - Cidadania: o trabalho da memória. Belo Horizonte (MG): São Paulo LTr, 2010;

GOMES, Ângela de Castro. Cidadania e Direitos do Trabalho. Rio de Janeiro: Zahar, 2002.

GOMES, Ângela de Castro. Retrato falado: a Justiça do Trabalho na visão de seus magistrados. Revista de Estudos Históricos, Rio de Janeiro, v. 1, n. 37, p. 55-80, jan./jun. 2006.

LARA, Silvia Hunold; MENDONÇA, Joseli Maria Nunes. Apresentação. In: LARA, Silvia Hunold; MENDONÇA, Joseli Maria Nunes (Org.). Direitos e Justiça no Brasil - Ensaios de História Social. Campinas: Unicamp, 2006, p. 9-22.

MENEZES, Ulpiano Bezerra de. Culturas Políticas e Lugares de Memória. In: CAIXETA, Maria Cristina Diniz; DINIZ, Ana Maria Matta Machado; CUNHA, Maria Aparecida Carvalhais (Org.). Anais do IV Encontro Nacional da Memória da Justiça do Trabalho - Cidadania: o trabalho da memória. Belo Horizonte/São Paulo - LTr, 2010 .

MOREL, Regina de Moraes. Magistrados do Trabalho no Brasil: entre a tradição e a mudança. Revista Estudos Históricos, Rio de Janeiro, n. 37, p. 29-53, jan./jun. 2006.

MUNAKATA, Kazumi. A legislação trabalhista no Brasil. São Paulo: Brasiliense, 1981;

NEGRO, Antonio Luigi. O que a Justiça do Trabalho não queimou: novas fontes para o estudo do trabalho no século XX. Politéia - História e Sociedade, Vitória da Conquista, v. 6, n.1, p. 193-209, 2006. 
SCHMIDT, Benito Bisso (Org.). Trabalho, Justiça e Direitos no Brasil: pesquisa histórica e preservação das fontes. São Leopoldo: Oikos, 2010.

SILVA, Fernando Teixeira da. Nem crematório de fontes, nem museu de curiosidades: Por que preservar os documentos da Justiça do Trabalho. In: BIAVASCHI, Magda Barros; LÜBBE, Anita; MIRANDA, Maria Guilhermina (Org.). Anais do I Encontro Nacional da Memória da Justiça do Trabalho - Memória e preservação de documentos: direitos do cidadão. São Paulo: LTr, 2007. 